\title{
Os dilemas do desenvolvimento: um olhar para o rural
}

\author{
Monica NARDINI ${ }^{1}$ \\ Eduardo Garcia SOUZA ${ }^{2}$ \\ Flávio Sacco dos $\mathrm{ANJOS}^{3}$
}

\section{RESUMO}

A definição e a aplicação do desenvolvimento não é um consenso no meio acadêmico e político, ao contrário, é um tema muito amplo e polêmico. O objetivo deste artigo foi o de abordar essas diferentes concepções, atreladas ao meio rural brasileiro, buscando vincular as abordagens a alguns exemplos práticos. Para tanto, discutiu-se sobre alguns dos principais enfoques do desenvolvimento lançando mão de referenciais teóricos. Percebe-se que apesar de ser um tema bastante discutido há décadas no meio acadêmico, ainda não há uma aplicação prática efetiva, com algumas poucas exceções, de políticas que realmente favoreçam o desenvolvimento rural, territorial e sustentável.

Palavras-chave: desenvolvimento rural; desenvolvimento sustentável; desenvolvimento territorial.

\section{The dilemmas of development: a look at the rural areas}

\begin{abstract}
The definition and application of development is not a consensus in the academic and political milieu, on the contrary, it is a very broad and controversial topic. The objective of this article was to approach these different conceptions, linked to the Brazilian rural environment, seeking to link the approaches to some practical examples. In order to do so, we discussed some of the main development approaches using theoretical references. It can be seen that despite being a topic that has been discussed for many decades in the academic world, there is still no effective practical application, with a few exceptions, of policies that really favor rural, territorial and sustainable development.
\end{abstract}

Keywords: rural development; sustainable development; territorial development.

\section{INTRODUÇÃO}

Publicado no Brasil no começo do novo milênio o Dicionário de Desenvolvimento (Sachs, 2000) resgata a trajetória de mais de meio século sobre um tema gerador de eterna controvérsia. Trata-se de livro coletânea que reúne contribuições de diversos autores, a exemplo de Gustavo Esteva. Ao introduzir sua reflexão, este escritor e ativista mexicano alude a uma particularidade da comunicação verbal dos brasileiros. Nesse país, como adverte Esteva, para

\footnotetext{
${ }^{1}$ Doutoranda no Programa de Pós-Graduação em Sistemas de Produção Agrícola Familiar, Universidade Federal de Pelotas. Email: moninardini@yahoo.com.br

${ }^{2}$ Mestre em Desenvolvimento Territorial e Sistemas Agroindustriais, Universidade Federal de Pelotas Email: admeduardogarcia@gmail.com

${ }^{3}$ Professor do Programa de Pós-graduação em Sistemas de Produção Agrícola Familiar e do Departamento de Ciências Sociais Agrárias, Universidade Federal de Pelotas Email: saccodosanjos@gmail.com
} 
dizer sim e aceitar alguma coisa, os brasileiros dizem "não", fazendo uso do conhecido "pois não".

Esta figura ilustrativa foi adotada para comentar que a maior parte das pessoas e dos estudiosos do assunto, ao referirem-se à ideia de desenvolvimento, dizem exatamente o contrário. Ou seja, não se trata de definir precisamente o que é desenvolvimento, mas de estabelecer o seu oposto, em outras palavras, a sua própria negação. Esteva se reporta ao discurso de investidura do presidente Truman, em seu segundo mandato, pronunciado no dia 20 de janeiro de 1949, momento em que, pela primeira vez, se emprega a palavra subdesenvolvimento, antítese óbvia da ideia de desenvolvimento. Segundo suas próprias palavras,

O subdesenvolvimento começou, portanto, no dia 20 de janeiro de 1949. Nesse dia, dois bilhões de pessoas se tornaram subdesenvolvidas. Em realidade, desde então deixaram de ser o que eram, em toda sua diversidade, e se converteram em um espelho invertido da realidade dos outros: um espelho que as despreza e as envia para o final da fila, um espelho que reduz a definição de sua própria identidade, a de uma maioria heterogênea e diversificada, aos termos de uma minoria pequena e homogeneizante. (ESTEVA, 2010, p.2).

Escrever sobre desenvolvimento é tratar de um tema polêmico, multidisciplinar e transversal (SACCO DOS ANJOS, 2016). Segundo Favareto (2006), se procuramos a gênese da ideia de desenvolvimento encontraremos seu vínculo ligado a termos como evolução e progresso, noções que podem ser observadas já nos filósofos gregos como Aristóteles e Lucrécio. Por outro lado, o conceito de progresso modificou-se com o tempo e o termo usado nesse período não corresponde ao entendimento atual. Segundo Theodor Adorno (1992), é durante o Iluminismo que pela primeira vez a humanidade se vê como agente responsável pelo progresso. A partir desse entendimento, buscamos empreender não uma revisão exaustiva da ideia de progresso e sua genealogia, mas, elucidar alguns aspectos que contribuíram para sedimentar uma ideia de desenvolvimento.

Com efeito, a interpretação cada vez mais racional do mundo ajudou a alavancar a compreensão da possibilidade de mudança social, de uma caminhada progressiva da humanidade. Nesse contexto, a ideia de progresso, precursora do desenvolvimento, surge durante o século XVIII com o movimento Iluminista e será fortalecida mais tarde, no século XIX, com o positivismo e a ascensão da ciência (BRESSER-PEREIRA, 2014).

Essas concepções contribuíram, em parte, para uma leitura evolucionista da sociedade, na qual é construída a imagem da existência de sociedades primitivas que devem evoluir gradativamente até atingir patamares tidos como 'mais civilizados'. Influenciado por Comte e Darwin, Herbert Spencer é um dos principais difusores do chamado "darwinismo social". 
Segundo ele, as sociedades em seu princípio são homogêneas e tendem a heterogeneidade à medida que evoluem:

Como se observa nas tribos bárbaras atuais, a sociedade, nas suas formas primitivas e inferiores, é um agregado homogêneo de indivíduos que têm o mesmo poder e exercem idênticas funções: a única diferença observada nestas últimas é a que acompanha a diferença de sexos. Todos os homens são guerreiros, caçadores, pescadores, fabricantes de utensílios, construtores; todas as mulheres se ocupam em iguais serviços; cada família se basta a si mesma, e, fora dos casos de agressão ou de defesa pode viver aparte das demais. Em breve, porém, no progresso da evolução social se encontra uma diferenciação incipiente entre o governo e os governados (SPENCER, 2002, p. 30).

Tais teses foram fortemente contestadas, pois como coloca Pierre Clastres (2004) as sociedades arcaicas não estão no caminho para se tornarem sociedades superiores. Ainda assim, em maior ou menor medida esse sistema de pensamento irá refletir em diversas ideias posteriores, como a noção de desenvolvimento. Segundo Furtado (2013, p. 96, destaque no original), essa maneira otimista de conceber o processo histórico com vistas a um futuro melhor e na evolução de um sistema social "induz à busca de um agente privilegiado — a classe operária, o empresário, a nação, o Estado —, «negatividade» capaz de aprofundar as contradições e precipitar o futuro, ou vetor do progresso". De tal forma, pode-se afirmar que diversos autores incorporam um entendimento evolucionista da sociedade.

Para Boaventura Santos (2002), essa racionalidade trata-se de uma "monocultura do tempo linear”, onde a história tem um único sentido e unívoca direção. Conforme o autor citado, essa direção tem sido formulada de diversas formas como: "progresso, revolução modernização, desenvolvimento, crescimento, globalização", declarando, assim, como atrasado aquilo que é assimétrico em relação ao que é visto como avançado, segundo a norma temporal (SANTOS, 2002, p. 247).

É somente após a Segunda Guerra que a noção de progresso vai dar lugar ao desenvolvimento. Até então a ideologia do progresso técnico e científico e o crescimento econômico eram vistos como as bases para o avanço humano. Não se trata de uma grande ruptura, mas de uma transformação do conceito. O avanço técnico-científico e o crescimento econômico são vistos como insuficientes para o avanço social e passam a ser acompanhados das dimensões social e cultural, além de econômica (ALMEIDA, 1999).

A “consciência do atraso" dos países subdesenvolvidos é o ponto de partida da reflexão sobre o desenvolvimento, que se configura primeiramente como política antes que como problema acadêmico (FURTADO, 2013). O contraste entre as nações ricas e industrializadas e as nações pobres não industrializadas fica evidente no pós-guerra. A receita do bem-estar social é atrelada então a altos níveis de industrialização e urbanização, à tecnificação da agricultura e 
ao crescimento da produção material, um receituário que se traduziria em desenvolvimento (ESCOBAR, 2007). Assim, esses indicadores guiariam o vaticínio entre países desenvolvidos e subdesenvolvidos, entre primeiro e terceiro mundo.

$\mathrm{Na}$ academia, o desenvolvimento passa a incorporar o debate em trabalhos que objetivavam explicar as razões das desigualdades entre os países e suas divergências de trajetória, tendo como expoentes Rostow e Rosentein Rodan, professores do Massachusetts Institute of Technology (FONSECA, 2015). Rostow (1961) contribuiu de maneira contundente para a leitura evolucionista do desenvolvimento, com a publicação de Etapas do Desenvolvimento Econômico: um manifesto não comunista. Este autor explicava as etapas percorridas pelas nações, desde sociedades com economia de base agrícola até fatalmente atingir a fase do consumo de massas, coroamento do processo de desenvolvimento. Assim, a industrialização dos países traria um crescimento automático e cumulativo (SUNKEL, 2000).

José Luís Fiori (1998) afirma que nesse período o desenvolvimento diferencia-se da ideia do mero crescimento, pois ele passa a ser entendido como um processo passível de ser induzido politicamente e que busca transformações estruturais e institucionais, além da aceleração do crescimento e da acumulação capitalista. Ou seja, passa-se a aceitar a intervenção de um fator extra mercado para sustentar o crescimento, processo que se dá com a consolidação do desenvolvimentismo na década de 1950.

Apesar da relação umbilical entre progresso e desenvolvimento, este último não deixou de se modificar ao longo do tempo e de introduzir novos aspectos e críticas às compreensões anteriores. O grande número de adjetivações (sustentável, humano, regional, territorial) busca alargar o conceito e ampliar esse debate decididamente multidisciplinar. Enquanto objeto de análise dá margem a diversas interpretações que priorizam desde aspectos materiais como produção e consumo, até pontos de vista que o interpretam sob critérios de renda, escolaridade e expectativa de vida.

Isso significa dizer que é possível avaliar o mesmo objeto considerando critérios totalmente distintos como o Produto Interno Bruto (PIB) ou o Índice de Desenvolvimento Humano (IDH). Mais ou menos como na fábula O Economista e o Rei da Belíndia de Edmar Bacha (1974), onde um economista avalia a taxa de crescimento da nação fictícia de Belíndia sob três critérios distintos. Cada critério adotado irá revelar uma realidade diferente. Crescimento alto ou baixo, tudo depende do ponto de vista. A medida, entretanto, é só um reflexo da maneira como o termo (desenvolvimento) é interpretado. Nesse sentido, compreender as diferentes interpretações e as mudanças que ocorreram sobre esse entendimento 
ao longo do tempo busca não só revelar sua importância histórica, mas também incitar alternativas teóricas de análise.

Durante a década de 1940, com a emergência da Economia do Desenvolvimento, um ramo da economia que buscou estudar o desenvolvimento, tal noção passa a ser objeto de pesquisas científicas, cujos resultados embasaram políticas públicas em diversas partes do mundo. No início visto como sinônimo de crescimento, reinando a tese de que primeiro era preciso fazer a economia crescer, para depois distribuir (SANTOS et al., 2012).

Neste contexto, a ideia era de que, nos países subdesenvolvidos, como o Brasil, para atingir o desenvolvimento, a agricultura precisava fornecer os recursos necessários para a indústria, através da oferta de mão de obra e matéria prima barata (SACCO DOS ANJOS, 2016). No entanto, são hoje evidentes os equívocos desse enfoque. O que se viu foi o aprofundamento dos desequilíbrios regionais e o agravamento do quadro social. Com o tempo, cada vez mais, ficou nítido que o crescimento econômico, ao mesmo tempo em que pode contribuir para que se alcance uma situação de bem-estar, pode igualmente ampliar as desigualdades sociais (FAVARETO, 2006).

O objetivo deste artigo é abordar algumas destas diferentes perspectivas conceituais do desenvolvimento, aludindo ao rural brasileiro e dando ênfase para algumas questões importantes que orientam a formulação e aplicação deste conceito. Discutem-se algumas das mudanças que o conceito de desenvolvimento sofreu com o passar dos anos, passando de sinônimo de crescimento econômico, para o acréscimo de adjetivações, que incorporam a essa noção outras dimensões (ambiental, social, cultural, territorial) da questão (SACHS, 1995; SEN 2000). As novas concepções de desenvolvimento surgem da necessidade de superação da visão produtivista, que gerou/vem gerando, diversos impactos ambientais e sociais bastante negativos sobre o modo de vida e sobre as condições sociais das populações do campo.

Refletir sobre algumas destas concepções do desenvolvimento, é o que a seguir trataremos, iniciando pelas considerações a respeito do desenvolvimento rural. Posteriormente, debate-se a ideia de desenvolvimento sustentável, desenvolvimento humano e territorial. Cabe ressaltar que não se pretende aqui um esgotamento do tema, tarefa essa extremamente ampla e, portanto, fora do alcance a que se propõe o trabalho.

\section{O DESENVOLVIMENTO RURAL}

O objetivo desta seção é explicitar a evolução que o conceito de desenvolvimento rural sofreu até chegar às discussões atuais, através de algumas de suas principais abordagens 
teóricas. Para tanto, faremos uma contextualização do debate conceitual e das abordagens de diferentes pesquisadores.

O modelo desenvolvimentista, incorporado aos rumos da agricultura brasileira a partir de 1960, através da chamada Revolução Verde, deu-se de forma desigual. Foi voltado para o aumento produtivo e privilegiou as regiões Sul e Sudeste e as culturas orientadas para o mercado internacional, principalmente a soja (GAZOLLA, 2004; GONÇALVES NETO, 1997; SACCO DOS ANJOS, 2016), bem como o milho, citros, algodão e cana de açúcar. A opção pelo uso intensivo de capital e de tecnologia, difundido através das tecnologias da Revolução Verde, por um lado, resultou no aumento da produção, tanto em virtude de incrementos na produtividade (verticalização), quanto pela expansão da fronteira agrícola (horizontalização). Por outro lado, gerou também inúmeros problemas ambientais, acentuando as desigualdades sociais no campo, além da desvalorização dos conhecimentos tradicionais.

Segundo Fonseca (2015), o desenvolvimentismo seria uma proposta baseada essencialmente em três pilares. (1) Projeto nacional: traçar uma estratégia com vistas ao futuro da nação; (2) Intervencionismo: interferência do Estado para viabilizar o projeto; (3) Industrialização: o progresso técnico e a modernização seriam os motores do crescimento econômico (inclusive para o setor primário). É interessante observar que, na década de 1960, Bresser-Pereira (1968) iria identificar o caminho para o desenvolvimento social no Brasil justamente através da formação industrial dos países. Esse desenvolvimento não passaria de uma mobilidade de classe, com a formação de administradores e empregados de nível médio absorvidos pela ascensão da indústria e da vida urbana. Paulatinamente se impõe a tese do abandono do mundo rural enquanto lócus da existência social.

Sacco dos Anjos (2003, p. 37) esclarece que essas mudanças trouxeram (e ainda trazem) consequências ao meio rural, sobretudo no caso das propriedades mais fragilizadas, que têm poucas probabilidades de inserção mercantil, tornando-se vítimas do "darwinismo social". Surgiram então discussões sobre novas formas de se pensar o desenvolvimento rural, especialmente a partir de 1990. Alguns fatores contribuíram para a emergência do debate em torno do desenvolvimento rural, e para sua legitimidade, entre eles: o reconhecimento da relevância da agricultura familiar como categoria política; atuação do Estado no meio rural, mudanças de âmbito político e ideológico e as preocupações em torno da sustentabilidade ambiental (SCHNEIDER, 2010).

Muitas organizações e lideranças ainda confundem desenvolvimento rural com desenvolvimento agrícola. É necessário compreender que estes não são sinônimos. A 
adjetivação "rural" alude ao bem-estar e as condições de vida das pessoas que vivem no campo ou em espaços não densamente urbanizados. Não obstante, o termo "agrícola", volta-se, estritamente, para o aumento da produtividade e da produção de cultivos e criações, podendo resultar em situações opostas ao desenvolvimento rural (NAVARRO, 2001; SACCO DOS ANJOS, CALDAS, 2008). Esse é o caso da lógica de produzir cada vez mais com cada vez menos gente. A expulsão prematura é vista como algo banal ou lógico. Os desertos verdes de monoculturas que avançam sobre a geografia nacional são a prova cabal dessa tendência.

Muitas ações e políticas agrícolas, com esse entendimento unificado e simplista de desenvolvimento rural estão voltadas para as culturas de exportações, as políticas de acesso ao crédito, e os subsídios às exportações, a exemplo da controvertida Lei Kandir, que tantos prejuízos trouxe aos estados exportadores do Brasil desde que foi implantada no começo dos anos noventa. Alguns exemplos nos ajudam a mostrar as abissais distâncias que separam desenvolvimento agrícola de desenvolvimento rural.

Em pesquisa realizada no município de Jaguarão, no extremo sul do Rio Grande do Sul, Nardini (2018), constatou que, apesar de ter ocorrido naquele município um incremento considerável na área plantada com a soja nos últimos dez anos, esse aumento não resultou em melhorias diretas nas condições de vida da população, senão justamente o contrário. Os prejuízos foram exaltados por atores locais ao mencionarem a destruição do campo nativo e o aumento no uso de agrotóxicos.

De acordo com Sacco dos Anjos (2003, p. 277):

[...] há que prestar muita atenção a esses novos movimentos que, no limite, questionam os postulados clássicos nos quais figura a tese da inexorabilidade da associação entre "industrialização" e "urbanização" ou de "desenvolvimento econômico" com "desruralização", entendida aqui como desaparição de pequenas localidades (aspas no original).

O autor ressalta ainda a importância de superar a tendência de que a modernização da agricultura transforme a população rural em clientela das políticas assistenciais ou refém de práticas clientelísticas. No seu entendimento, trata-se de reconhecer a importância de uma abordagem multifuncional dos espaços rurais, de obrar em favor da preservação dos recursos naturais e de apoiar estratégias de diversificação das atividades rurais, sejam elas agrícolas ou não-agrícolas.

As abordagens do desenvolvimento rural aproximam-se, quanto aos seus objetivos, priorizando aspectos como: igualdade econômica e social, respeito à cultura local e conservação ambiental. Com a inclusão da questão ambiental na agenda pública e o início das discussões 
territoriais no planejamento rural, os debates sobre um "novo" desenvolvimento rural ganham impulso (RIBEIRO, ANDION, BURIGO, 2015; SCHNEIDER, 2004).

As discussões mais recentes a respeito do desenvolvimento rural se deram em torno de alguns eixos, com ênfase: na erradicação da pobreza rural, na importância dada aos atores sociais, na unidade de referência ou escala territorial e na preocupação crescente com a preservação ambiental (SCHNEIDER, 2004; SCHNEIDER, SHIKI, BELIK, 2010).

Não há dúvidas que o consenso entre os pesquisadores do meio rural é sobre a importância da agricultura familiar como fomentadora do desenvolvimento rural e da economia local dos espaços em que está inserida. Neste contexto, surgem novas abordagens, onde o desenvolvimento rural pode ser entendido como um conjunto de ações que objetivam diminuir a vulnerabilidade dos agricultores em relação aos agentes externos, aumentando a o seu grau de autonomia (CONTERATO, SCHNEIDER, WAQUIL, 2008). A seguir, examinam-se os contornos do que se veio a chamar de desenvolvimento sustentável.

\section{O DESENVOLVIMENTO SUSTENTÁVEL}

O tema da sustentabilidade foi incorporado à agenda conceitual de economistas, ambientalistas, acadêmicos a partir dos anos 1980, quando as vicissitudes do modelo hegemônico de desenvolvimento adotado eram mais do que evidentes. A produção não podia mais ser vista de forma isolada, dissociada da natureza. As formas de apropriação dos recursos naturais passam a ser seriamente questionadas. Caporal e Costabeber (2004) lembram que antes desse período, na década de 1970, os resultados dos métodos convencionais de desenvolvimento já se mostravam falhos para dar conta de temas palpitantes como a desigualdade e a exclusão social. Mesmo com o crescimento do Produto Interno Bruto (PIB), as avaliações dos resultados indicavam que tais métodos estavam ocasionando graves danos ao meio ambiente.

Publicado em 1962, A primavera silenciosa, de Rachel Carson, expõe a tragédia do uso de agrotóxicos, sobretudo do uso dos organoclorados para a natureza e para os seres humanos em geral, seja para os que vivem no campo, seja para os que vivem nas cidades. Rachel Carson, escritora, bióloga e pesquisadora Norte-Americana, ironicamente, morreu de câncer, na primavera de 1964. Pouco tempo antes havia discursado no congresso Norte-Americano, exortando os parlamentares daquele país a adotarem políticas de proteção à saúde humana e ao meio ambiente. Em boa medida, sua posição influenciou o banimento do DDT, do BHC e de 
outros produtos de elevada toxidade, assim como os rumos do debate em torno da questão da sustentabilidade.

O ano de 1972 é especialmente emblemático para essa abordagem. Nesse ano aconteceram dois eventos que se tornariam marcos do debate sobre o desenvolvimento sustentável: a publicação de Limites do Crescimento, pelo Clube de Roma e a conferência de Estocolmo (BRÜSEKE, 1995). Cresce o entendimento de que as estratégias de desenvolvimento adotadas no pós-guerra causaram severos impactos no meio ambiente. Tais discussões alertavam para a importância de se pensar novas formas de desenvolvimento, com menor agressão ao ambiente. No entanto, o conceito de desenvolvimento sustentável surge timidamente em 1979, no Simpósio das Nações Unidas sobre Inter-Relações entre Recursos, Ambiente e Desenvolvimento, também em Estocolmo (VEIGA, 2010).

Gliessman (2000) considera que, mesmo com significados distintos, há uma concordância de que a sustentabilidade tem uma base ecológica. A sustentabilidade ecológica precisa de um contexto social e econômico capaz de lhe servir como suporte para poder se consolidar. A prova da sustentabilidade sempre estará no futuro, tornando-se impossível ter certeza se determinadas práticas são efetivamente sustentáveis. Para Sacco dos Anjos, Caldas e Hirai (2008), a sustentabilidade deve ser entendida em seu caráter multidimensional, no âmbito social, ambiental, econômico, político, ético, e cultural e como um projeto contraditório e complexo do ponto de vista de sua implementação.

José Eli da Veiga (2010) define um novo entendimento do termo desenvolvimento, associado à concepção da sustentabilidade. Relata a existência de dois gêneros de sustentabilidade que fazem parte das discussões entre os economistas convencionais. Em primeiro lugar está a corrente dos que acreditam que é possível combinar conservação ambiental e crescimento econômico. Segundo esta vertente, os recursos podem ser substituídos através do progresso científico e tecnológico. As ideias de Solow e seus adeptos foram denominados de "sustentabilidade fraca". Para os defensores desta perspectiva "o que é preciso garantir para gerações futuras é a capacidade de produzir, e não manter qualquer outro componente mais específico da economia” (VEIGA, 2010, p. 123).

A segunda linha de pensamento, citada por Veiga (2010), integra pesquisadores identificados com a "sustentabilidade forte". Estes entendem que grande parte dos recursos naturais é esgotável, propondo que os danos ambientais provocados sejam compensados. Como o mercado de recursos naturais não gera seus preços relativos, a saída, segundo eles, seria a cobrança de cotas de emissão, favorecendo a criação de mercados de direito de poluir. 
Dentro da discussão do tema sustentabilidade podem-se incluir os debates em torno de uma visão que defende a ideia de produzir alimentos de forma sustentável e garantir a sobrevivência do agricultor familiar como um desafio necessário. Deponti (2001, p. 84) define desenvolvimento sustentável como sendo:

[...] um novo projeto social que promova a transformação econômica, tecnológica, política e ambiental do atual modelo de desenvolvimento, para que as necessidades básicas sejam satisfeitas, tanto das presentes como das futuras gerações, procurando não degradar os recursos naturais e, assim, apresentar maiores condições de manutenção ao longo do tempo.

Caporal e Costabeber (2002) enunciam seis dimensões basilares para pensar o desenvolvimento rural sustentável, agrupados em três grandes níveis. O primeiro nível integraria três dimensões: ecológica, econômica e social. O segundo nível integraria a dimensão cultural e a dimensão política. No terceiro nível estaria assentada a dimensão ética. Na visão destes autores a dimensão ecológica representaria os esforços no sentido da conservação e melhoria dos recursos naturais. A dimensão social contempla a melhoria da qualidade de vida e distribuição igualitária dos recursos, sem perder de vista a dimensão econômica de viabilizar a geração de renda. A dimensão cultural pressuporia o respeito e a valorização da cultura local, ao passo que a dimensão política contempla os valores democráticos e participativos, garantindo o exercício pleno da cidadania. A dimensão ética evoca o sentido moral de nossas práticas, seja pela conscientização acerca da responsabilidade que deve mover nossas condutas, seja no sentido de solidariedade para com a presente e as futuras gerações. Já para Navarro (2001), o adjetivo "sustentável" acrescido à palavra desenvolvimento representa apenas atribuir maior peso ao componente ambiental.

Lima (2003) esclarece que a amplitude da crise contemporânea requer um projeto de sustentabilidade que ultrapasse as fronteiras do mercado, integrando uma pluralidade de aspectos sociais. Na sua acepção, "uma sustentabilidade liderada pelo mercado e apoiada em mudanças técnicas e demográficas será sempre reducionista e, portanto, necessariamente insustentável" (LIMA, 2003, p. 107).

Abramovay (2012) compreende que é preciso ir além da economia verde, voltada apenas para a redução do uso dos materiais e da energia nos processos produtivos. Ele fala sobre a ideia de uma nova economia, centrada nos limites dos ecossistemas e na ética das escolhas relacionadas ao uso dos recursos. Cita dois aspectos centrais para comprovar sua visão: a expansão da produção e do consumo, que encontram limites efetivos dos ecossistemas e no funcionamento da economia, os quais têm contribuído de forma muito limitada para a redução das desigualdades. Este autor alude o paradoxo de que mesmo que a produção tenha crescido consideravelmente, nunca se viu 
tanta pobreza, questionando, outrossim, o sentido de crescimento da economia em detrimento do aumento da qualidade de vida.

Favareto (2006) adverte para a necessidade de unir, na compreensão sobre os processos de desenvolvimento, as diversas disciplinas - geografia, sociologia, economia - em discussões que envolvam temas como meio ambiente, instituições e estruturas sociais, assuntos que geralmente são abordados de forma isolada ou fragmentada. Tais questões demandam um pensamento multidisciplinar e transversal, não sendo possível avançar seguindo um viés disciplinar e cerrado ao diálogo entre diferentes áreas de conhecimento.

Ainda assim, mesmo que a agenda ambiental tenha se tornado questão central no debate sobre o desenvolvimento, por vezes, tais adjetivações parecem representar apenas novas roupagens para os mesmos fins. De acordo com Latouche (2014), a nova nomenclatura procura esconder os malefícios do crescimento, sendo um pleonasmo e um oximoro simultaneamente: "Pleonasmo porque o desenvolvimento já é um self-sustaining growth (crescimento durável por si só), para Rostow, o grande ideólogo do conceito. Oximoro porque o desenvolvimento não é nem durável nem sustentável" (LATOUCHE, 2014, p. 220). Em outras palavras, a sustentabilidade também pode funcionar como um eufemismo ao desenvolvimento, escondendo na retórica da responsabilidade ambiental o contínuo aumento do crescimento e acumulação:

Notadamente, a despeito da retórica conservacionista, os pressupostos do desenvolvimento sustentável não rompem com a ideologia do crescimento organizacional, pelo contrário, em seu reconhecido pilar econômico-financeiro da lucratividade, presume a possibilidade da contínua e indefinida acumulação dos lucros. Ao contrário dos processos de desenvolvimento biológico que, por estarem inseridos no ciclo da vida, iniciam sua degeneração ao atingirem a maturidade, os pressupostos do desenvolvimento sustentável não preveem limites para o crescimento econômico (VIZEU, KANASHIRO, MENEGHETTI, SEIFERT, 2012, p. 758).

Um exemplo das distorções geradas por esse entendimento é a prática do greenwhashing (ABRAMOVAY, 2012), onde as a sustentabilidade se torna estratégia de marketing, sendo apenas um novo meio de obter lucro. É necessário que, além de trazer à tona a discussão ambiental, sejam observadas as deformidades que surgem dessa prática. Como lembra Favareto (2006), esse é um debate de grande valor ético. E, por isso mesmo, é necessário evidenciar práticas obtusas que atuem travestidas de ambientalismo. Basta relembrar das tentativas de identificar os desertos verdes de monocultura de eucalipto, que grassam pelos quatro quadrantes do país como expressão de um "reflorestamento" que desconhece que a ideia de floresta é justamente sinônimo de diversidade.

A discussão em torno de um desenvolvimento que incorpore a noção de sustentabilidade envolve, portanto, um contexto mais amplo, pressupondo aspectos sociais, políticos, culturais 
e econômicos. A revolução verde trouxe o aumento produtivo, mas acentuou a degradação ambiental, e notadamente não atingiu seu principal objetivo que era o de eliminar a fome no mundo. Agora, muitos autores falam em uma revolução duplamente verde, ou seja, produzir mais alimentos, mas de uma forma diferente, de forma ambiental e socialmente sustentável.

Parece inegável, portanto, que os métodos de produção convencionais utilizados na agricultura estão exaurindo os recursos naturais do planeta, além de perpetuarem a má distribuição de alimentos. A emergência dessas preocupações torna imperativas outras formas de produzir, como no caso da agroecologia ou da produção orgânica. Ainda que ocupem um espaço minoritário dentro das ações promovidas pelo Estado brasileiro, sua importância é crescente quando vista pela ótica dos consumidores. Outras preocupações, especialmente no que diz respeito às oportunidades e condições de vida dos indivíduos, também reforçam outros olhares sobre a questão do desenvolvimento. Esse é o foco da próxima seção.

\section{DESENVOLVIMENTO HUMANO}

Uma importante contribuição sobre a questão do desenvolvimento humano nos é dada através da obra de Sen (2000). Ele analisou o papel do desenvolvimento através de uma perspectiva mais ampla que a comumente adotada, a qual invariavelmente leva em conta o viés econômico, através de aspectos como Produto Interno Bruto (PIB), renda, industrialização dentre outros. Nesse sentido, Sacco dos Anjos (2016) relata que:

A concessão do Prêmio Nobel de Economia, em 1998, ao prof. indiano Amartya Sen marca um verdadeiro divisor de águas, não somente do ponto de vista de propor um novo olhar sobre fenômenos como a fome, a pobreza ou a desigualdade, mas de romper com toda uma tradição intelectual que associava o desenvolvimento ao crescimento do produto interno bruto, da renda per capita, da industrialização ou do grau de urbanização de uma dada sociedade (p. 19).

Sen estabelece um conjunto de aspectos ligados à sua acepção de desenvolvimento, acrescentando ao parâmetro econômico a qualidade de vida e a expansão das liberdades. Considera a liberdade o principal fim, mas também os meios do desenvolvimento (SEN, 2000). Conforme essa concepção, mesmo que os cidadãos de alguns países, dentre eles o Brasil, tenham o Produto Nacional Bruto (PNB) per capita mais alto do que outros, como a Índia, a nação asiática apresenta uma expectativa de vida mais elevada, evidenciando a desconexão entre a renda per capita e a liberdade de usufruir de uma vida mais longa.

Apesar de reconhecer a importância dos mecanismos de mercado para o crescimento econômico, Sen (2000) ressalta que é preciso analisar, também, as exclusões desencadeadas pela sociedade norteada unicamente pelos humores dos mercados. Para Sen (2000, p. 28) "os fins e os meios do desenvolvimento requerem análise e exames minuciosos para uma 
compreensão mais plena do processo de desenvolvimento". O autor utiliza o termo "agente" para representar alguém que atua e ocasiona modificações. Além disso, suas ações são avaliadas de acordo com seus objetivos. Contrapõe-se à tese de que o desenvolvimento econômico, como convencionalmente ocorre, pode suprimir tradições e culturas. Contrariamente, defende que:

[...] se um modo de vida tradicional tem de ser sacrificado para escapar-se da pobreza devastadora ou da longevidade minúscula, então são as pessoas diretamente envolvidas que tem de ter a oportunidade de participar da decisão do que deve ser escolhido (SEN, 2000, p. 47).

A questão central é que o "desenvolvimento tem de estar relacionado, sobretudo, com a melhora da vida que levamos e das liberdades que desfrutamos" (SEN, 2000, p. 29). Por outro lado, é necessário que a vida dos indivíduos seja coerente com seus anseios e não por meio de imposições. Nesse sentido, possibilitar que os atores sociais desenvolvam suas habilidades e se empenhem em atividades que lhes são atrativas é algo fundamental, bem como a participação da sociedade em pautas públicas. O cerceamento das liberdades individuais acontece quando os atores sociais têm sua autodeterminação limitada, isto é, não podem decidir e intervir nos seus próprios destinos (seja por escolhas de vida, seja por participação democrática).

Em tais termos, o desemprego, por exemplo, não significa apenas uma diminuição de renda. Ele agrega efeitos cerceadores da liberdade, limitando a iniciativa e o desenvolvimento das habilidades individuais. Para Sen (2000), a falta de emprego pode promover a exclusão social de alguns grupos, levando à perda de autonomia e autoconfiança, além de influenciar na saúde física e psicológica daquele que se encontra nessa situação. A privação da liberdade econômica está diretamente ligada à liberdade social e à política. É preciso interpretar as relações entre renda e desenvolvimento e perceber de que forma essas categorias se correlacionam, sem a superficialidade da mera mensuração da renda per capita.

As ideias de Amartya Sen, ao lado de Mahbub ul Haq, tornaram-se um marco referencial no entendimento dos processos de desenvolvimento. Adotado como nova métrica pelas Nações Unidas, o Índice de Desenvolvimento Humano (IDH), passou a tomar o lugar do PIB para interpretação e avaliação do desenvolvimento. Segundo o Programa das Nações Unidas para o Desenvolvimento (2013), “desenvolvimento humano”, consonante a tese do de Sen, há que ser visto como um processo de ampliação das liberdades dos indivíduos:

O processo de expansão das liberdades inclui as dinâmicas sociais, econômicas, políticas e ambientais necessárias para garantir uma variedade de oportunidades para as pessoas, bem como o ambiente propício para cada um exercer na plenitude seu potencial. Assim, desenvolvimento humano deve ser centrado nas pessoas e na ampliação do seu bem-estar, entendido não como o acúmulo de riqueza e o aumento da renda, mas como a ampliação do escopo das escolhas e da capacidade e da liberdade de escolher. Nesta abordagem, a renda e a riqueza não são fins em si mesmas, mas meios para que as pessoas possam viver a vida que desejam (PNUD, 2013, p. 23). 
O IDH integra três aspectos essenciais, quais sejam: a esperança de vida ou longevidade das pessoas, os níveis de educação ou escolaridade e a renda auferida pelos indivíduos. Com base nessas dimensões é possível estabelecer uma métrica do desenvolvimento humano, com faixas de desenvolvimento que variam de zero (desenvolvimento muito baixo) até um (muito alto). Obviamente que, como outras métricas, está sujeita a falhas e equívocos. Entrementes, a mudança de enfoque contribui para pensar o mundo rural sob um novo paradigma que coloque em pauta as condições de vida das populações analisadas e não somente as questões materiais ligas à esfera da produção e do consumo. A incorporação da perspectiva espacial ao debate sobre o desenvolvimento inaugura uma nova era de reflexões, tema que trataremos na seção subsequente.

\section{O DESENVOLVIMENTO TERRITORIAL}

No final da década de 1980 e início da década de 1990 ganha destaque um novo enfoque sobre o desenvolvimento: a abordagem territorial. Esta concepção considera os territórios em seus aspectos mais amplos: ambientais, econômicos e sociais (GALVANESE; FAVARETO, 2014), com os quais admite-se que o território concerne um conjunto de relações sociais, econômicas e políticas convergentes (GAZOLLA, 2004; SACCO DOS ANJOS; CALDAS; HIRAI, 2008). Com efeito, a concepção territorial se apresenta como uma tentativa de romper com a abordagem dicotômico-dualista convencional, assim como um esforço de superação aos limites da abordagem setorial do desenvolvimento (SACCO DOS ANJOS, CALDAS, HIRAI, 2008; SCHNEIDER, 2004).

Essa abordagem impõe a necessidade de se reconsiderar a ideia de território. É importante fazer algumas ponderações importantes. O trabalho clássico de Raffestin (1993) destaca uma diferença existente entre espaço e território. O primeiro é meramente físico, o segundo pressupõe uma atuação sobre o espaço:

É essencial compreender bem que o espaço é anterior ao território. O território se forma a partir do espaço, é o resultado de uma ação conduzida por um ator sintagmático (ator que realiza um programa) em qualquer nível. Ao se apropriar de um espaço, concreta ou abstratamente (por exemplo, pela representação), o ator "territorializa" o espaço.

Para Silva (2013) o conceito de território evoca múltiplos significados e objetiva explicar uma realidade de relações complexas entre diferentes atores sociais e destes com o meio em que estão inseridos. O autor define o território como um ambiente de construção social e de poder estabelecido, estando marcado por recursos físicos específicos e por valores históricos e culturais que determinam a identidade dos indivíduos a ele pertencentes. O território 
é a relação do homem com o meio natural, é decorrência das relações sociais e são as categorias sociais que o adaptam aos seus interesses e aos do capital. Pode ser um município, região, ou definido por características sociais, econômicas, históricas, semelhantes (GAZOLA, 2004). Por outra parte, Patrício e Gomes (2012, p. 104) entendem que:

O âmbito local é o espaço privilegiado para se atingir um Desenvolvimento Rural Sustentável com racionalidade. Isto porque as ações que levarão a esse desenvolvimento serão respostas da comunidade local aos problemas vividos e as soluções que ela irá apresentar para os seus problemas de produção, consumo, ocupação do espaço e aproveitamento local de suas potencialidades naturais e humanas.

Schneider (2004, p. 94) considera que "entre os estudiosos parece haver um certo consenso de que esta talvez seja a unidade de referência mais adequada para se estudar e analisar os processos gerais de reestruturação societários e seus impactos locais". Para este autor, foram duas as razões que levaram à inclusão da perspectiva territorial nos debates do desenvolvimento rural: o desgaste do enfoque regional e a prevalência da economia de escopo sobre a de escala no desenvolvimento de algumas atividades econômicas. Schneider (2004, p. 108) entende que o conceito de território está baseado no significado das "relações dos indivíduos com o espaço em que se processa sua sociabilidade e atividades produtivas e nas formas de apropriação e dominação que decorrem dessas relações”.

$\mathrm{Na}$ abordagem territorial, o espaço de ação dos indivíduos é apontado como essencial para o tratamento dos dilemas e para a busca de soluções dos problemas enfrentados. Trata-se de encontrar sendeiros de um desenvolvimento descentralizado e cada vez mais apoiado nos próprios atores locais. Pereira e Carrieri descrevem um movimento contrário à ideia de territorialidade, a desterritorialização, que segundo os autores "viria para esvaziar o território (e os espaços ocupados) de seu conteúdo relacional e particular, que promoveria uma identificação entre os indivíduos e as organizações” (PEREIRA, CARRIERI, 2005, p. 04).

Juntamente com a abordagem territorial, as concepções do desenvolvimento sustentável propugnam estratégias de desenvolvimento “a um só tempo, economicamente viáveis, socialmente justas e ambientalmente sustentáveis, baseadas em potencialidades e alternativas econômicas provenientes das bases de recursos dos diferentes territórios" (GALVANESE; FAVARETO, 2014, p. 73).

Colocar as energias de um local ou região a serviço de uma cadeia produtiva, como por exemplo a de uma commodity, sem qualquer preocupação com a distribuição da riqueza produzida ou mesmo com os impactos socioambientais decorrentes dessa expansão é fazer um pouco de "mais do mesmo". Concretamente, longe estamos de alterar o padrão de desenvolvimento hegemônico desde que se impôs tal visão no auge dos anos 1970 e nas décadas 
subsequentes. No entanto, a incorporação da noção de território como base dos projetos de desenvolvimento, traz novas perspectivas e olhares cruzados sobre a realidade.

Segundo Pecqueur (2009), expoente francófono da abordagem territorial do desenvolvimento, essa guinada territorial busca uma integração entre todos os atores do território, incluindo agentes públicos privados identificados com objetivos de longo prazo. As estratégias de desenvolvimento devem estar ancoradas em aspectos sociais e culturais da região e serem impulsionadas de forma endógena.

Nesse contexto, o enfoque sobre os recursos do território e a identidade territorial (BENKO, PECQUEUR, 2001; FLORES, 2006; FONTE, RANABOLDO, 2007; PECQUEUR, 2009; DALLABRIDA, 2012) ganha força para pensar o desenvolvimento rural. De acordo com Uribe e Vargas (2007), tais processos de desenvolvimento podem buscar a exploração de recursos naturais em práticas de turismo, ecoturismo e agroturismo. Outra alternativa é no sentido de criar estratégias que busquem valorizar produtos elaborados a partir de métodos tradicionais e que tenham reconhecimento social por expressar a cultural de determinada região, como, por exemplo, o bocadillo veleño, onde a "producción de este dulce obedece principalmente a técnicas heredadas de padres a hijos o aprendidas por los antigos empleados de las fábricas artesanales de tipo familiar” (URIBE, VARGAS, 2007, p.124)

Esse entendimento favorece a emergência de estratégias que acompanhem as características de um dado território e parecem especialmente interessantes para as regiões rurais (ACAMPORA, FONTE, 2007; DALLABRIDA, 2012). Conforme Canclini (1990), o moderno e o tradicional podem conviver harmonicamente e inclusive estabelecerem uma relação positiva. Diferentemente do desenvolvimentismo, onde o rural seria apenas um degrau na escada para o urbano, é possível que atividades exercidas no campo sejam um fator dinamizador também da cidade, como é o exemplo do turismo rural.

Também as indicações geográficas, por exemplo, fazem parte de um escopo de desenvolvimento em que há uma relação direta entre os atores do território, as especificidades locais e a inserção em mercados mais exigentes, por intermédio do que convencionalmente se chama "sinais distintivos de mercado". Essas certificações exercem um poder de diferenciação e proteção da origem ou procedência dos produtos, bem como do saber-fazer dos produtores rurais. Ademais, podem também canalizar externalidades positivas para o território em questão. Tal concepção parte da premissa que as relações sociais devem funcionar como um recurso que dá suporte à criação de estratégias locais. 
A construção coletiva da qualidade demanda que diferentes atores possam interagir e construir pontes entre si. Essa união cria um maior poder de articulação para os atores sociais que conseguem expandir sua atuação mediante a conexão com maior número de pessoas, amplificando a sua rede (GRANOVETTER, 1983). Nesse sentido, conectar-se com círculos sociais diferentes é importante também no sentido de aumentar a informação para o grupo.

Sacco dos Anjos (2016, p. 22), lembra a iniciativa da produção do arroz Terra Livre, como um exemplo desse tipo de estratégia de desenvolvimento:

Gosto do exemplo da produção de arroz orgânico no Rio Grande do Sul - o arroz Terra Livre produzido por diversos assentamentos de reforma agrária. Trata-se de uma rica experiência de aprendizagem, onde o Movimento dos Sem Terra evidencia que não somente reconheceu a importância dos mercados como instrumento de inclusão social e de viabilização dos assentamentos, mas também porque se mostrou aberto no sentido de contrair relações de confiança com diversos atores, incluindo empresas de certificação, prefeituras municipais, agentes do comércio e inclusive com grandes superfícies de varejo.

A coesão social tem sido considerada um importante elemento para fazer eclodir experiências extremamente inovadoras no âmbito dos territórios. A nova orientação pressupõe subverter a lógica da competitividade entre os lugares e recolocar a solidariedade como motor de iniciativas territorial e culturalmente referenciadas. A inovação e a aprendizagem recaem justamente na construção e o fortalecimento de laços entre os atores sociais, e entre os atores e as instituições (públicas e privadas, dentro e fora do território).

\section{CONSIDERAÇÕES FINAIS}

Nem o progresso técnico-científico, nem o crescimento econômico, que serviriam como elos propulsores para eliminar as desigualdades sociais e permitir a instauração do bem-estar coletivo, parecem ter cumprido bem o papel a que se propuseram. Ao contrário, o aumento nos níveis concentração de riqueza, de miséria e crescente esgotamento dos recursos naturais indicam que os elevados níveis de urbanização e industrialização não se traduziram em melhorias no plano social. Compreender o desenvolvimento a partir desses moldes levou regiões com características absolutamente distintas a serem avaliadas sob a mesma óptica, sob a mesma métrica, além de serem conduzidas a proferir uma equívoca sentença entre modernos e atrasados.

Neste artigo, a ênfase esteve posta no afã de evidenciar as origens de uma noção que suscita enorme polêmica, assim como as diversas adjetivações construídas ao longo dos últimos 50 anos. As diversas acepções servem para mostrar dimensões distintas que não raras vezes se apresentam enfrentadas enquanto aos objetivos que postulam alcançar os atores e suas organizações. Ao falar de sustentabilidade e de territorialidade deixamos patente a necessidade 
de superar a dicotomia rural/urbano, assim como a visão setorial que considera que a erradicação dos problemas dos espaços não densamente urbanizados passa por fomentar cadeias produtivas e pela verticalidade de processos regidos pelo produtivismo.

Para que se compreenda verdadeiramente o que é desenvolvimento, deve-se partir do pressuposto de que, apesar de seus diversos sinônimos, o conceito não pode ser visto de forma fragmentada. Estratégias de desenvolvimento que visam reproduzir padrões supostamente auspiciosos em outras latitudes estão certamente fadadas ao fracasso. Todavia, quando o caminho a ser seguido passa pela implicação de grande parte dos atores, e quando as escolhas se dão através do exercício pleno da democracia, do compartilhamento de informações e de compromissos recíprocos, os territórios podem se converter no que Putnam (2009) define como "regiões cívicas" e promissoras, capazes de construir instituições fortes, abertas à inovação e aos processos de aprendizagem.

\section{REFERÊNCIAS}

ABRAMOVAY, R. Muito além da economia verde. São Paulo: Ed. Abril, 2012.

ACAMPORA, T.; FONTE, M. Produtos típicos, estrategias de desarrollo rural y conocimiento local. Opera, n. 7, p. 191 -212, 2007.

ADORNO, T. W. Progresso. Lua Nova, n. 27, p. 217-236, 1992.

ALMEIDA, J. A problemática do desenvolvimento sustentável. Redes, v. 1, n. 2, 1999.

BACHA, E. L. El economista y el Rey de Belindia: Una fábula para tecnócratas. Cuadernos de Economía, v. 11, n. 33, p. 60-64, 1974.

BENKO, G.; PECQUEUR, B. Os Recursos de Territórios e os Territórios de Recursos. Florianópolis: Geosul, v. 16, n. 32, p. 32-50, jul./dez., 2001

BRESSER-PEREIRA, L. C. Desenvolvimento e Crise no Brasil: 1930 e 1967. Zahar, 1968.

BRESSER-PEREIRA, L. C. Desenvolvimento, progresso e crescimento econômico. Lua Nova, n. 93, 2014.

BRÜSEKE, F. J. O problema do desenvolvimento sustentável. Desenvolvimento e natureza: estudos para uma sociedade sustentável. São Paulo: Cortez, 1995.

CANCLINI, N. G. Culturas híbridas Estratégias para entrar y salir de la modernidad. Mexico: Grijalbo, 1990.

CAPORAL, F. R.; COSTABEBER, J. A . Análise Multidimensional da Sustentabilidade Uma proposta metodológica a partir da Agroecologia. Agroecol. e Desenv. Rur. Sustent., Porto Alegre, v.3, n.3, Jul/Set 2002.

CAPORAL, F. R.; COSTABEBER, J. A. Agroecologia e Extensão Rural: contribuições para a promoção do desenvolvimento rural sustentável. Brasília: MDA/SAF/IICA, 2004.

CARSON, R. Primavera Silenciosa. São Paulo: Melhoramentos, 1964. 
CLASTRES, P. A sociedade contra o Estado. Editora Cosac Naify, 2004.

CONTERATO, M. A.; SCHNEIDER, S.; WAQUIL, P. D. Desenvolvimento Rural no Estado do Rio Grande do Sul: uma análise multidimensional de suas desigualdades regionais. Redes, Santa Cruz do Sul, v. 12, p. 163-195, 2008.

DALLABRIDA, V. R. Da vantagem comparativa à vantagem diferenciadora: estratégias de especificação de ativos territoriais como alternativa de desenvolvimento. Desenvolvimento Regional em debate, v. 2, n. 1, p. 104-133, jul., 2012.

DEPONTI, C. M. Indicadores para avaliação da sustentabilidade em contextos de desenvolvimento rural local. 2001. Monografia (Especialização em Desenvolvimento Rural e Agroecologia). Programa de Pós-graduação em Desenvolvimento Rural, Universidade Federal do Rio Grande do Sul, Porto Alegre, 2001. Disponível em:

http://www.emater.tche.br/site/arquivos_pdf/teses/mono_Cidonea_Machado.pdf. Acesso em: 21 jul. 2016.

ESCOBAR, A. La invención del Tercer Mundo: construcción y deconstrucción del desarrollo. Caracas: Fundácion Editorial el pero y la rana, 2007.

ESTEVA, G. Development. In: SACHS, W. The Development Dictionary: a guide to Knowledge as power. New York: Zed Books, 2010.

FAVARETO, A. da Silva. Paradigmas do desenvolvimento rural em questão - do agrário ao territorial. São Paulo, Tese (Doutorado em Ciência Ambiental). Universidade de São Paulo, São Paulo, 2006.

FIORI, J. L. O capitalismo e suas vias de desenvolvimento. In: HADDAD, Fernando (org.). Desorganizando o consenso: nove entrevistas com intelectuais à esquerda. São Paulo: Fundação Perseu Abramo, 1998.

FLORES, M. A identidade cultural do território como base de estratégias de desenvolvimento - uma visão do estado da arte. Santiago: RIMISP, 2006.

FONSECA, P. C. D. Desenvolvimentismo: a construção do conceito. Texto para Discussão. Instituto de Pesquisa Econômica Aplicada (IPEA), 2015.

FONTE, M. RANABOLDO, C. Desarrollo rural, territorios e identidades culturales. Perspectivas desde América Latina y la Unión Europea. Opera, n. 7, p. 9-33, 2007.

FURTADO, C. Essencial Celso Furtado. Companhia das Letras, 2013

GALVANESE, C.; FAVARETO A. Dilemas do planejamento regional e as instituições do desenvolvimento sustentável. Revista Brasileira de Ciências Sociais, vol. 29, nº 84, p. 73 86, 2014.

GAZOLLA, M. Agricultura familiar, segurança alimentar e políticas públicas: uma análise a partir da produção de autoconsumo no território do Alto Uruguai/RS. Dissertação (Mestrado em Desenvolvimento Rural). Faculdade de Ciências Econômicas, Universidade Federal do Rio Grande do Sul, Porto Alegre, 2004.

GLIESSMAN, S. R. Agroecologia: processos ecológicos em agricultura sustentável. Porto Alegre: Ed. Universidade/UFRGS, 2000.

GONÇALVES NETO, W. Estado e agricultura no Brasil: política agrícola e modernização econômica brasileira 1960-1980. São Paulo: HUCITEC, 1997. 
GRANOVETTER, M. The strength of weak ties: A network theory revisited. Sociological theory, p. $201-233,1983$.

LATOUCHE, S. Existirá uma vida após o desenvolvimento? Estudos de Sociologia, v. 2, n. 16, p. 217-230, 2014.

LIMA, G. C. O discurso da sustentabilidade e suas implicações para a educação. Ambiente \& Sociedade. Vol. VI n ${ }^{\circ} .2$ jul./dez. 2003.

NARDINI, M. A face espúria de um grão dourado: impactos socioambientais da expansão da soja em Jaguarão, RS. Dissertação (Mestrado). Programa de Pós-Graduação em

Desenvolvimento Territorial e Sistemas Agroindustriais, Universidade Federal de Pelotas, Pelotas, 2018.

NAVARRO, Z. Desenvolvimento rural no Brasil: os limites do passado e os caminhos do futuro. Estudos Avançados. v. 15, n. 43, 2001.

PATRICIO, P. C.; GOMES, J. C. C. Desenvolvimento rural sustentável, planejamento e participação. Nera, Presidente Prudente, ano 15, No. 21, p. 100-113, jul./dez., 2012.

PECQUEUR, B. A guinada territorial da economia global. Política \& Sociedade, n. 14, p.79105, abr., 2009.

PEREIRA, D. C.; CARRIERI, A.P. Movimentos de desterritorialização e reterritorialização na transformação das organizações. RAE-eletrônica, v. 4, n. 1, Art. 13, jan./jul. 2005.

PROGRAMA DAS NAÇÕES UNIDAS PARA O DESENVOLVIMENTO (PNUD). Índice de Desenvolvimento Humano Municipal Brasileiro. Brasil: Série Atlas do

Desenvolvimento Humano no Brasil, 2013.

PUTNAM, R. D. Comunidade e democracia: a experiência da Itália moderna. 5 ed. 3 reimp.. Rio de Janeiro: Editora FGV, 2009.

RAFFESTIN, C. Por uma geografia do poder. Rio de Janeiro: Ática, 1993.

RIBEIRO, A. C.; ANDION, C.; BURIGO, F. Ação coletiva e coprodução para o desenvolvimento rural: um estudo de caso do Colegiado de Desenvolvimento Territorial da Serra Catarinense. Adm. Pública - Rio de Janeiro, p. 119-140, jan./fev. 2015.

ROSTOW, W. W. Etapas do desenvolvimento econômico (Um manifesto não-comunista). Rio de Janeiro: Zahar Editores, 1961.

SACCO DOS ANJOS, F. Abordagem territorial e desenvolvimento: tópicos sobre a natureza de um debate inacabado. In: BADALOTTI, R. M.; COMERLATTO, D. (orgs.). Território, territorialidades e estratégias do desenvolvimento regional. Passo Fundo: IMED, 2016.

SACCO DOS ANJOS, F. Pluriatividade e desenvolvimento rural no Sul do Brasil. Cadernos de Ciência \& Tecnologia, Brasília, v. 20, n. 1, p. 11-44, 2003.

SACCO DOS ANJOS, F.; CALDAS, N. V. O rural brasileiro: velhas e novas questões em debate. Teoria \& Pesquisa, v. 17, p. 49-66, 2008.

SACCO DOS ANJOS, F.; CALDAS, N. V.; HIRAI, W. G. Mercantilização da agricultura e insegurança alimentar no sul do Brasil. In: Congresso da Sociedade Brasileira de Economia, Administração e Sociologia Rural (SOBER), 46, 2008, Rio Branco. Anais[...] Rio Branco: SOBER, 2008.

SACHS, I. Em busca de novas estratégias de desenvolvimento. Estudos avançados, v. 9, n. 25, p. 29-63, 1995. 
SACHS, W. Dicionário do desenvolvimento: guia para o conhecimento como poder. Petrópolis, Rio de Janeiro: Vozes, 2000.

SANTOS, B. S. Para uma sociologia das ausências e uma sociologia das emergências. Revista crítica de ciências sociais, n. 63, p. 237-280, 2002.

SANTOS, E. L. et. al. Desenvolvimento: um conceito multidimensional. Desenvolvimento Regional em debate, Canoinhas, a. 2, n. 1, jul., p. 44-61, 2012.

SCHNEIDER, S. A abordagem territorial do desenvolvimento rural e suas articulações externas. Sociologias, Porto Alegre, a. 6, nº 11, jan/jun, p. 88-125, 2004.

SCHNEIDER, S. Situando o desenvolvimento rural no Brasil: o contexto e as questões em debate. Revista de Economia Política, v. 30, nº 3, p. 511-531, jul./set., 2010.

SCHNEIDER, S.; SHIKI, S.; BELIK, W. Rural development in Brazil: overcoming inequalities and building new markets. Rivista di Economia Agraria / a. LXV, n. 2, p. 225259, giu. 2010.

SEN, A. Desenvolvimento como liberdade. São Paulo: Cia. das Letras, 2000.

SILVA, S.P. Avanços e limites na implementação de políticas públicas nacionais sob a abordagem territorial no Brasil. Brasília: IPEA, 2013. [Texto para Discussão]

SPENCER, H. Do progresso, sua lei e sua causa. eBooksBrasil, 2002.

SUNKEL, O. Desenvolvimento, subdesenvolvimento, dependência, marginalização e desigualdades espaciais: por um enfoque totalizante. In: Cinqüenta anos de pensamento na CEPAL. Rio de Janeiro: Record/CEPAL, 2000-v. 2, p. 521-566, 2000.

URIBE, D. S., VARGAS, J. Valorización de la identidad territorial, políticas públicas y estrategias de desarrollo territorial en los países de la comunidad andina. Revista Opera, n. 7, p. 109-138, 2007.

VEIGA, J. E. da. Desenvolvimento sustentável: o desafio do século XXI. Rio de Janeiro: Garamond, 2010.

VIZEU, F.; KANASHIRO MENEGHETTI, F; SEIFERT, R. Por uma crítica ao conceito de desenvolvimento sustentável. Cadernos Ebape. br, v. 10, n. 3, 2012.

Nota 1: O terceiro autor agradece ao CNPQ pela concessão de bolsa de produtividade em pesquisa. 